220304

\title{
Five-Rule Effects in Young and Older Adults' Arithmetic: Further Evidence for Age-Related Differences in Strategy Selection
}

Patrick Lemaire and Mireille Lecacheur

\section{OpenEdition}

\section{Journals}

\section{Electronic version}

URL: http://journals.openedition.org/cpl/412

DOI: $10.4000 /$ cpl.412

ISSN: $1379-6100$

Publisher

Centre PsyCLÉ

\section{Electronic reference}

Patrick Lemaire and Mireille Lecacheur, «Five-Rule Effects in Young and Older Adults' Arithmetic:

Further Evidence for Age-Related Differences in Strategy Selection », Current psychology letters [Online] 12, Vol. 1, 2004 | 2004, Online since 22 March 2004, connection on 11 September 2020. URL : http:// journals.openedition.org/cpl/412 ; DOI : https://doi.org/10.4000/cpl.412

This text was automatically generated on 11 September 2020

(C) All rights reserved 


\title{
220304
}

\section{Five-Rule Effects in Young and Older Adults' Arithmetic: Further Evidence for Age-Related Differences in Strategy Selection}

\author{
Patrick Lemaire and Mireille Lecacheur
}

Submitted December 15, 2003

Revision March 16, 2004

Accepted March 19, 2004

On line March 22, 2004

This research is based on the facts that people use a variety of strategies to accomplish a cognitive task and select a given strategy on each problem. How do they choose among strategies on each problem has been an important question for cognitive psychologists. Previous research has documented a number of factors that affects strategy selection. Most studies have been carried out in young adults. As too few studies have investigated how strategy selection mechanisms change with age in adults, we ignore how older adults choose among strategies, which factors affect their strategy choices, and whether older adults' strategy selection is influenced by the same type of variables that influence young adults' strategy choices. The present research was conducted to address these issues in order to understand age-related differences in strategy selection, a general goal that we pursue in the context of arithmetic problem solving.

In arithmetic, researchers have been using two types of tasks to investigate cognitive strategies: production and verification tasks. In a production task, participants are presented with a series of problems (e.g., $8 \times 4,19 \times 23$ ) to solve, and the individual strategies used by participants are identified (with a variety of tools like videotape recordings or verbal protocols), as well as several characteristics of these strategies, 
such as their frequency, speed, or accuracy. In a verification task, participants are asked to verify a series of problems (e.g., $8 \times 4=32,69 \times 5=348$ ), and the effects of problem type (e.g., true problems, such as $8 \times 4=32$, or false problems, such as $8 \times 4=39$ ) on participants' latency and accuracy are analyzed. The use of multiple strategies and their adjustments to problem (or other task) features are inferred from the pattern of speed and accuracy that arise as a function of the factors that define the stimulus set and other experimental situations.

7 Previous research reported that younger people adjust their strategy use to problem and situation characteristics in arithmetic problem verification tasks. For example, Lemaire and Reder (1999) asked young adults to say whether arithmetic equations like $7 \times 49=341$ or $5 \times 68=343$ are true or false. They found that young adults were faster to verify so-called five/mismatch problems (i.e., problems including 5 as one operand and an answer not including 0 or 5 in the proposed answer, such as $49 \times 5=238$ ) than to verify so-called five/match problems (i.e., problems including 5 as one operand and 0 or 5 in the proposed answer, such as $5 \times 63=320$ ). This is consistent with the hypothesis that younger adults use two different strategies and adapt their strategy use to each type of problem. To verify five/match problems they used a complete-verification strategy which includes the following processes: encoding numbers in the equation, calculating correct solution in memory, comparing calculated and proposed answers, making a true/false decision, and responding. To reject five/mismatch problems they used a fiverule checking strategy in which detecting that the proposed answer did not include 0 or 5 as a unit digit dispensed with calculating the correct solution and comparing it with the proposed solution to quickly make a true/false decision.

Lemaire and Reder (1999) also observed that people were much faster when $75 \%$ of false, five problems were five/mismatch problems than when either $50 \%$ or $25 \%$ of false, five problems were five/mismatch problems. This latter result suggests that people used the five-rule checking strategy more often when there were more problems violating the five rule and less often when fewer problems violated the rule. In other words, participants adjusted or adapted their strategy use to changing rates of strategies as well as to problem characteristics. Such adaptivity of strategy use has been found in arithmetic problem verification tasks a number of times with other stimulus characteristics, such as the odd/even status of numbers or the splits between proposed and correct answers (Allen, Ashcraft, \& Weber, 1992; Allen, Smith, Jerge, \& Vires-Collins, 1997; Ashcraft \& Battaglia, 1978; Ashcraft \& Stazyk, 1981; De Rammelaere, Stuyven, \& Vandierendonck, 2001; El Yagoubi, Lemaire, \& Besson, 2003; Kreuger, 1986; Kreuger \& Hallford, 1984; Lemaire \& Fayol, 1995; Masse \& Lemaire, 2001; Pesenti, Thioux, Seron, \& De Volder, 2000; Stanescu-Cosson et al., 2000; Zbrodoff, 1999; Zbrodoff \& Logan, 2000; Zbrodoff \& Logan, 1990). Adaptivity of strategy use has also been found in arithmetic production tasks (e.g., LeFevre et al., 1996a \& b; Lemaire \& Lecacheur, 2001; Lemaire \& Siegler, 1995; Siegler \& Lemaire, 1997).

9 Age-related changes in strategy use and strategy selection have been fairly well documented in children (see Siegler, 1996, for a review). However, much less is known regarding these changes in older adults. Geary and Wiley (1991) analyzed verbal reports of younger and older adults in a simple addition production task. They observed differences in younger and older adults' strategy repertoire. Both age groups reported using retrieval (i.e., solving 9-4 by directly retrieving 5 from memory) and decomposition strategy (i.e., solving 7-4 by doing 7-2-2). Young adults used 
decomposing strategy on easier problems (7\%) more often than older adults (2\%) and retrieval less often overall than older adults ( $88 \%$ vs. $98 \%$ ). Also, young adults used verbal counting (i.e., counting out loud 12-1-1-1 to solve 12-3); older adults almost never used it. Similar age-related differences in strategy use were found on simple and complex subtraction problems (Geary, Frensch \& Wiley, 1993; Geary \& Lin, 1998).

Duverne and Lemaire (2003; see also Duverne, Lemaire, \& Michel, 2003; El Yagoubi, Lemaire, \& Besson, in press) tested age-related changes in strategy selection. They asked participants aged between 20 and $80+$ years to accomplish arithmetic problemverification tasks. More specificially, they tested age-related changes in split effects. In split effects, participants have better performance on large-split problems $(7+4<18$. True? false?) than on small-split problems $(6+3<11)$. Split effects have been interpreted as arising from participants' using different strategies on each type of small- and largesplit problems. Duverne and Lemaire found age-related decreased split effects, suggesting that older adults used only one strategy on all trials (i.e., they always calculated the correct answer before deciding whether the proposed answer was true or false) and young adults used one strategy on small-split problems (i.e., completeverification strategy) and another one on large-split problems (i.e., plausibility strategy by which they quickly decided that $7+4<18$ was true without calculating the correct sum of $7+4)$. In the present experiment, we aimed at testing the generality of this finding to another arithmetic effect, namely the five-rule effect.

11 The present experiment aimed at replicating five-rule effects in young adults and test whether older adults adjust their arithmetic problem verification strategies to both problem and situation characteristics. In particular, we tested the hypothesis that young and older adults differ in strategy selection so that older adults are less able than young adults to adjust their strategy use to problem and situation characteristics. It is possible that, given well-known decreased processing resources with age (e.g., Salthouse, 1996) and previous findings of Duverne and Lemaire (2003) on split effects, older adults are less able to calibrate their strategy choices so as to choose each strategy when it works best on each problem. To test this hypothesis, younger and older adults were asked to accomplish an arithmetic problem verification task like in Lemaire and Reder (1999). Participants were asked to say whether a series of complex arithmetic problems (e.g., 9x27=243) are true or false, and characteristics of problems as well as proportions of each problem type were manipulated. Half the problems were true (e.g., $4 \times 18=72$ ) and half were false (e.g., 4x18=79). Problems were either five problems (i.e., they included 5 as an operand like in $5 \times 18$ ) or non-five problems (e.g., $4 \times 18$ ), and there were two types of five false problems. Some problems respected the so-called five rule (i.e., $\underline{\mathrm{N}} \mathrm{x}=$ =product with a unit digit equal to 0 or 5 like in $5 \times 16=85$ ); other problems violated the five rule (e.g., $5 \times 18=93$ ). All participants were first tested under so-called equal ratio condition in which half of the false five problems respected the five rule. Then, half the younger and older participants were tested under the highmismatch ratio condition in which $75 \%$ of the false five problems violated the five rule, and half undertook the low-mismatch ratio condition in which $25 \%$ of the false five problems violated the five rule.

The hypothesis of age-related differences in strategy selection makes two sets of predictions. First, in younger adults, we expected to replicate Lemaire and Reder (199)'s findings that participants are (a) faster on five than on non-five problems, (b) on five mismatch problems (i.e., those violating the five rule) than on five match problems, 
and that (c) the match-mismatch difference is larger under the high-mismatch ratio condition and smaller under the low-mismatch ratio condition, as compared to the equal ratio condition. Second, we tested these predictions in older adults. Similar findings in younger and older adults would show that strategy selection mechanisms remain stable with age and are affected by similar variables in younger and older adults. Alternatively, different findings in older adults would suggest age-related changes in strategy selection in older adults.

Several patterns of alternative age-related differences in participants' use of verification strategies were possible. First, contrary to young adults, older adults are no longer flexible and adaptive in their strategy use and do not use the five-rule checking strategy to reject false mismatch problems. This predicts equal levels of speed and accuracy for both types of problems violating and respecting the five rule. Second, like younger adults, older people use the complete-verification and five-rule checking strategies on each match and mismatch problems, respectively, but much less adaptively. That is, they are not as systematic as younger adults in their Problem $\mathrm{x}$ Strategy assignement which would be seen in match-mismatch difference of smaller magnitude in older adults. Finally, age-related differences in fine tuning strategy use to ratio conditions would be observed if magnitudes of match-mismatch differences as a function of the proportions of problems violating/respecting the five rule change only in younger adults or change much less in older adults than in younger adults. Such an outcome requires significant five-rule effects under equal mismatch condition in both age groups and may be possible if older adults' cognitive resources are too short to (consciously or unconsciously) notice and adjust to changing rates of false five problems. A final potential pattern that was tested in older adults includes no significant match-mismatch difference under equal-ratio condition and a significant corresponding difference under high-mismatch condition. Such an outcome is a-priori possible if older adults use the five-rule violation only when this violation is salient, such as in the high-mismatch condition.

MethodParticipants

14 This experiment included 48 participants, 24 younger adults and 24 older adults. Younger adults (14 females) were undergraduate college students who received course credit for participating in the experiment. Their mean age was 23.6 years (range: 18.6 to 30.5$)$. Older adults (16 females) were volunteers who attended courses given at the University of Provence for senior citizens and who were given a short book on cognitive aging written in French by the first author (Lemaire, 1999) to thank them for their participation. Their mean age was 71.4 years (range $=60.6$ to 81.6). At the beginning of the experiment, we collected information about participant's sex, age (in years and months), and the number of years of formal education. The mean self-rating for health status ranged between good and excellent for participants of each age group (means were 6.41 , on a $1-7$ scale with $1=$ poor and $7=$ excellent), $F<1$, and the number of years of formal education was equal in the two age groups, $F<1$ (means were $=13$ and 12, for younger and older adults, respectively). All older adults took the Mini-Mental State Examination (MMSE; Folstein, Folstein, \& McHugh, 1975) for potential dementia screening. All individuals had scores higher than 27 (mean: 29.4); therefore, none were excluded from the study.

15 At the end of the experiment, participants completed a French version of the Mill-Hill Vocabulary Scale (MHVS; Raven, 1951) so as to control for their verbal ability. The 
MHVS consists of 33 items distributed across three pages. Each item was a target word followed by six proposed words, and the task consisted of identifying which of the proposed words had the same meaning as the target word. The number of correct items represented the level of verbal ability. Next, participants completed both the addition and the subtraction-multiplication subtests of the French Kit (French, Ekstrom, \& Price, 1963) which provided us with an independent, paper-and-pencil test, assessment of their arithmetic skill. Each subtest consisted of two pages of problems for a total of four pages. All participants were given two minutes per page, and were instructed to solve the problems as fast and accurately as possible. Number of correct answers on each of the addition and the subtraction-multiplication tests were summed to yield a total arithmetic score. Older adults obtained better performance in the Mill-Hill Vocabulary Scale (means were 25.8 and 29.8 in younger and older adults, respectively, $F(1,46)=14.80$, and comparable arithmetic skills (mean numbers of correctly solved problems were 98 and 92 in younger and older adults, respectively, $F(1,46)=1.93$, ns).

Stimuli

16 The stimuli were multiplication problems presented in a standard form (i.e., $\underline{a} \times \underline{b}=\underline{c}$ ), with the operands $\underline{a}$ and $\underline{b}$ being either single-digit or double-digit numbers. The whole set of equations comprised 512 single- $\mathrm{x}$ double-digit problems (see Appendix $\mathrm{C}$ in Lemaire \& Reder, 1999). There were two types of problems: Nonfive and five problems. Nonfive problems were used for purposes of comparison with time to verify five problems and to assess participants' arithmetic skills. Five problems always used one number equal to five, the other being a two-digit number. Nonfive problems consisted of one single-digit number and one double-digit number. Each participant saw the complete set of 512 problems, half of which were true and half false problems. True and false problems had the same operands and differed only in whether the value given as the product was correct.

17 For the five false problems, those that matched (respected the five rule) had incorrect answers that were off by \pm 5 from the correct answer (e.g., $5 \times 14=75$ ); mismatch problems had incorrect answers that were off by \pm 7 or \pm 3 from the correct answer (e.g., 5x18=93). For the nonfive problems, incorrect answers were off by \pm 7 or \pm 3 from the correct answer in order to have splits of equal magnitude across five and nonfive problems and to have both five and nonfive false problems violating the parity of the correct answer. All false problems violated parity, regardless of whether or not they violated the five rule, a condition that favors participants' use of five-rule checking strategy (Masse \& Lemaire, 2001). Across conditions, we counterbalanced or controlled the side of the double-digit operand, the size of the correct answer, and the size and direction of splits.

18 The participants in the high-mismatch condition were presented with $75 \%$ fivemismatch problems after participating in two blocks of equal proportions of mismatch and match problems. In the low-mismatch condition, the equal ratio blocks were followed by a block in which only $25 \%$ of the false five problems mismatched. In both high- and low-mismatch conditions, half the problems had an even non-five operand (e.g., 5x14), and half the problems had an odd non-five operand (e.g., 5x13).

19 For each ratio condition, the set of 256 problems was divided into two blocks of 128 problems each, with there being an equal number of each type of problems (e.g., five vs. nonfive problems). For the unequal ratio conditions (i.e., low- and high-mismatch conditions), each block respected the proportion of high- and low-mismatch problems. 
Procedure

20 The problems were presented in a 48-point Palatino font in the center of a computer screen. At the beginning of each trial the word PRET (ready in French) was displayed in the center of the screen for $750 \mathrm{msec}$. The equations were then displayed horizontally in the center of the screen in the form $\underline{a} \times \underline{b}=\underline{c}$. The symbols and numbers were separated by spaces equal to the width of one character. The equation remained on the screen until the participant responded. A clock began timing at the onset of the equation and stopped when the participant pressed one of two keys on the computer keyboard, corresponding to true or false. The software (E-Prime) controlled stimulus display and latency collection. The participants were instructed to use their left and right index fingers to respond, and the assignment of response to keys was counterbalanced across participants. The participants were encouraged to respond as quickly as possible without making mistakes. No particular strategies were mentioned. The equal ratio was always presented first, followed by one of the unequal-ratio conditions. The participants were given a brief rest period between blocks. Within each block, problems were randomly presented. Before the experiment began in earnest, the participants were given a block of 20 practice (similar but not identical to experimental) problems to familiarize them with the apparatus and procedure.

Results

21 For the purpose of comparison and clarity, we report analyses on five versus nonfive problems and on false five problems separately. Preliminary analyses revealed that Block (first or second block of each equal- and unequal-ratio conditions) and odd versus even non-five operands had no significant main effects, nor did they enter into any interaction, so we collapsed data over these factors for all analyses. Unless otherwise noted, differences are signficant at an alpha level of $\underline{p}<.05$ or greater.

speed and accuracy for five versus nonfive problems

22 We first compare the participants assigned to the low-versus the high-mismatch ratio conditions in which the proportion of five rule violations was $50 \%$ to ensure that our random assignement did not produce groups of individuals with different arithmetic skills. Table 1 presents mean correct RTs and percent errors as a function of future assignment to treatment condition, true versus false problems, and whether the problems involved five as an operand. The participants' mean correct response times (RTs) and percent errors were analyzed in a 2 (age: young and older adults) x 2 (ratio: high and low mismatch) $\times 2$ (response: true and false) $\times 2$ (problem: five and nonfive) ANOVAs, with repeated measures on the last three factors. 
Table 1 : Mean Reaction Times (in Milliseconds) and Percent Errors (SDs in parentheses) for True and False Problem Verification Under Equal-Ratio Condition in Young and Older Adults.

\begin{tabular}{|c|c|c|c|c|c|c|c|c|c|c|c|c|}
\hline \multirow[b]{3}{*}{ Protkem } & \multicolumn{6}{|c|}{$\begin{array}{l}\text { Growup to be Assigned bo } \\
\text { the High-Mismusch condition }\end{array}$} & \multicolumn{6}{|c|}{$\begin{array}{l}\text { Group ks be Assignod is } \\
\text { the Lum-Mismutch oondition }\end{array}$} \\
\hline & \multicolumn{2}{|c|}{ True } & \multicolumn{2}{|c|}{ False } & \multicolumn{2}{|l|}{ M } & \multicolumn{2}{|l|}{ True } & \multicolumn{2}{|l|}{ Folue } & \multicolumn{2}{|l|}{ M } \\
\hline & RT & PE & RT & $\mathrm{PE}$ & RT & PE & $\mathrm{RT}$ & $P B$ & RT & PE & $\mathrm{RT}$ & PE \\
\hline & \multicolumn{12}{|c|}{ Younger Adults } \\
\hline Nonfive & $33 \times 0(1631)$ & $8.5(5.0)$ & 202816093 & $4.062 .3\}$ & $3153(15) 93$ & $6.3(2.8)$ & $3804(398)$ & $7.8(4.3)$ & $2829(96)$ & $(2.92 .2)$ & $332 \times 115 t)$ & $53(2.2)$ \\
\hline Five & $2914(1450)$ & $2.2(2.4)$ & $2390(1248)$ & $4.6 \times 4.5)$ & $2652 \times 1308)$ & $3.4(2.1)$ & $324 \times 1066)$ & $2(0 \times 4.4)$ & $2442(760)$ & $4.0(2.0)$ & $2841(887)$ & $30(2.2)$ \\
\hline \multirow[t]{2}{*}{$M$} & 3147 & 53 & 2658 & 4.3 & 2903 & 4.8 & 3534 & 4.9 & 2636 & 3.5 & 3oss & 4.2 \\
\hline & \multicolumn{12}{|c|}{ Otder Adults } \\
\hline Nonfive & $404(6749)$ & $9.60 .99)$ & $3149(931)$ & $2.9(2.4)$ & $35 n \pi(813\}$ & $6.3(5.3)$ & $3291(1085)$ & 6.9(4.9) & $296 \times(960)$ & $3.3(3.0)$ & $31300611)$ & $5,1(3,1)$ \\
\hline Fire & $3547(610)$ & $4,6(4.3)$ & $2736 \times 700)$ & $3.4(2.2)$ & $3141(602)$ & $4 .(x) 28)$ & 2908 (1006) & $30 \times 3.5$ & 2462 (956) & $20 x(6)$ & 27159977 & $26(1.9)$ \\
\hline M & $37 \times x$ & 7.1 & 2942 & 3,1 & 3369 & 5,1 & 3130 & 50 & 2715 & 2.6 & 2022 & 38 \\
\hline
\end{tabular}

There was a significant effect of True/False, $F(1,44)=85.14$, MSe $=283443$, and of Five/ Nonfive problems, $F(1,44)=96.10, M S e=88033$. True problems were verified more slowly than false problems ( $3402 \mathrm{~ms}$ vs. $2738 \mathrm{~ms}$ ), presumably due to participants' calculating the correct answer before comparing it with the proposed answer for all true problems and quickly rejecting false, five mismatch problems because the unit digit of the proposed answer differed from 0 or 5 . Moreover, five problems $(2837 \mathrm{~ms})$ were verified more quickly than nonfive problems $(3302 \mathrm{~ms})$ replicating previously found greater speed advantages of five problems (e.g., Campbell \& Graham, 1985; Geary et al., 1993; LeFevre et al., 1996a \& b; Lemaire \& Reder, 1999). The main effect of age was not significant $(F<1)$.

The pattern of error data paralleled those of latencies. Five problems (3.2\%) produced fewer errors than did nonfive problems (5.8\%), $F(1,44)=25.29, M S e=11.01$, and true problems produced more errors than did false problems (5.6\% vs. $3.4 \%), F(1,44)=14.19$, $M S e=18.06$. Finally, the Response $\mathrm{x}$ Problem interaction was significant, $F(1,44)=23.43$, $M S e=16.06$. Tukey HSD tests showed that the difference between true and false problems was significant $(5.2 \%)$ for nonfive problems only. No other main or interaction effects were significant on either latencies or percent errors.

In summary, analyses of speed and accuracy of five and nonfive true and false problems showed that the random assignment of younger and older participants to ratio did not create groups with spuriously different arithmetic skills. We also confirmed the expectation of better performance on five problems over nonfive problems and better performance on false problems than on true problems. Most interestingly, there were no age-related differences in these response and problem effects, thereby confirming that any age-related differences on false five problems do not come from one group of participants being less skilled at solving five problems. These results replicate Lemaire and Reder's (1999) findings and extend them to older adults.

speed and accuracy for false five problems

The goal of this second series of analyses was to determine (1) whether both young and older people use the five rule to reject false five problems, (2) whether, for a given participant, the size of the five effect is affected by the proportion of trials violating the five rule. Table 2 presents mean correct latencies and percent errors for false five problems. These data were analyzed using a 2 (Age: young and older adults) x 2 (ratio: high and low mismatch) x 2 (treatment: equal and unequal mismatch) x 2 (five rule: match and mismatch problems) ANOVAs, with repeated measures on the last two factors. 
Table 2 : Mean Reaction Times (in Milliseconds) and Percent Errors (SDs in parenteses) for False Five Problem Verification under Equal - and Underqual - Ratio Conditions in Young and Older Adults.

\begin{tabular}{|c|c|c|c|c|c|c|c|c|}
\hline \multirow[b]{3}{*}{ Problem } & \multicolumn{4}{|c|}{$\begin{array}{l}\text { Group wo be Assigned to } \\
\text { the High-Mismalch condition }\end{array}$} & \multicolumn{4}{|c|}{$\begin{array}{l}\text { Group to be Assigned wo } \\
\text { the Low-Mismatch condition }\end{array}$} \\
\hline & \multicolumn{2}{|c|}{ Equal Ratio } & \multicolumn{2}{|c|}{ High-mismatch ratio } & \multicolumn{2}{|c|}{ Equal ratio } & \multicolumn{2}{|c|}{ Lon-mismatch ratio } \\
\hline & RT & $\mathrm{PE}$ & RT & $\mathrm{PE}$ & $\mathrm{RT}$ & PE & RT & $\mathrm{PE}$ \\
\hline & \multicolumn{8}{|c|}{ Younser.Adults } \\
\hline Match & $2540(1400)$ & $7.8(9.0)$ & $2211(1057)$ & $3,6(4,2)$ & $2682(865)$ & $5.7(5.3)$ & $1967(526)$ & $4.3(3.8)$ \\
\hline Mismateh & $2241(1116)$ & $1.3(2.8)$ & $1750(670)$ & $1.4(3.0)$ & $2202(705)$ & $2.3(4.6)$ & $1757(410)$ & $1.5(1.8)$ \\
\hline \multirow[t]{2}{*}{$\begin{array}{l}\text { Five } \\
\text { Effects }\end{array}$} & $299^{*}$ & $6.5^{* 1}$ & $461=7$ & $2.3^{*}$ & $480^{\circ}$ & 3.4 & 211 & 2.8 \\
\hline & \multicolumn{8}{|c|}{ Oldsr Adults } \\
\hline Match & $2767(693)$ & $5.7(3.5)$ & $2306(634)$ & $4.2(4.9)$ & $2503(937)$ & $2.6 \times(3.2)$ & $2232(854)$ & $3.0 \times 3,0)$ \\
\hline Mismatch & $2705 \times 735)$ & $1,000(1.5)$ & $2112(519)$ & $1.6(1.6)$ & $2421(979)$ & $1.3(2.1)$ & $2314(873)$ & $1.000 .1)$ \\
\hline \multicolumn{9}{|l|}{ Five } \\
\hline & 62 ns & $4.7 \mathrm{~ns}$ & $194^{*}$ & $2.6^{*}$ & 82 & 1.3 & -81 & 2.0 \\
\hline
\end{tabular}

Two main effects were significant. First, there was significant five rule effects, such that match problems were rejected more slowly than mismatch problems (2401 ms vs. $2187 \mathrm{~ms}), F(1,44)=19.47, M S e=112240$. This five-rule effect replicate Lemaire and Reder (1999)'s five-rule effects and occurred presumably because participants used two different strategies on each match and mismatch problems and adapted their strategy use to each type of problem. They used a complete-verification strategy (i.e., including the following processes: encoding, calculating the correct product, comparing proposed and calculated products, making true/false decision, and responding) on five match problems; they used a fast five-rule checking strategy (i.e., not including search of correct products) on five mismatch problems. The second significant main effect was that of treatment, $F(1,44)=59.37, M S e=146918$, showing faster latencies under unequal mismatch condition than under equal-mismatch condition ( $2081 \mathrm{~ms}$ vs. $2508 \mathrm{~ms})$. This occurred because participants accomplished the problem-verification task first under equal-ratio condition and, second, under unequal ratio condition. When they were tested under unequal ratio condition, participants were more familiar with the task.

Most interestingly, four interactions were significant: Age x Five rule, $F(1,44)=9.55$, $M S e=112240$; Age $\mathrm{x}$ Ratio $\times$ Five Rule, $F(1,44)=5.28, M S e=146918$; Ratio $\times$ Treatment $\mathrm{x}$ Five rule, $\underline{F}(1,44)=22.19, M S e=17815$; and Age $\mathrm{x}$ Treatment $\mathrm{x}$ Five rule, $F(1,44)=7.83$, $M S e=17815$. These interactions were further analyzed with breakdown analyses conducted for each age group, with Ratio, Treatment as between-subject factors, and Five rule as a within-subject factor. Moreover, significance of five effects (match mismatch problems) was tested via planned comparisons in each age Ratio $\mathrm{x}$ Treatment condition.

In younger adults, the following effects were significant: Treatment, $F(1,22)=31.57$; Five rule, $F(1,22)=17.83$; and Ratio $x$ Treatment $x$ Five rule, $F(1,22)=15.19$. These effects were explained by the facts that (a) match problems were rejected more slowly than mismatch problems (2350 ms vs. $1988 \mathrm{~ms}$ ), (b) participants were faster under unequal than under equal condition (1921 ms vs. $2416 \mathrm{~ms}$ ), and (c) five effects increased in the high-mismatch (from $299 \mathrm{~ms}$ in the equal-ratio condition to $461 \mathrm{~ms}$ in the high- 
mismatch condition) and disappeared in the low-mismatch condition (from $480 \mathrm{~ms}$ in the equal-ratio condition to non-significant $211 \mathrm{~ms}$ in the low-mismatch condition).

In older adults, the following effects were significant: Treatment, $F(1,22)=28.52$; Ratio $\mathrm{x}$ Treatment, $F(1,22)=6.34$; and Ratio $\mathrm{x}$ Treatment $\mathrm{x}$ Five rule, $F(1,22)=7.55$. These effects were explained by the facts that (a) participants were faster under unequal than under equal condition ( $2241 \mathrm{~ms}$ vs. $2599 \mathrm{~ms}$ ), especially in the high-mismatch ratio condition (the equal-unequal differences were $527 \mathrm{~ms}$ and $189 \mathrm{~ms}$ under high- and low-mismatch conditions, respectively), and (b) five effects were never significant, except under the high-mismatch ratio condition in which the $194 \mathrm{~ms}$ five-rule effect was significant, $F(1,22)=5.98$. No other effects came out significant in latencies. Although participants committed few errors, similar analyses of mean percent errors did not compromise these conclusions. Significant effects were found for five rule, $F(1,44)=46.64, M S e=12.13$, and Treatment, $F(1,44)=7.38, M S e=8.77$. Participants made $3.8 \%$ fewer mistakes for mismatch than for match problems and $0.9 \%$ fewer mistakes under unequal-ratio than under equal-ratio condition. No other effects came out significant in error rates.

Discussion

In conclusion, the present results replicate Lemaire and Reder (1999)'s findings in young adults, and extend some of these to older adults. Both young and older adults were faster to verify false problems than true problems and five problems than nonfive problems. The present results also showed five-rule effects in young adults (i.e., they were faster in rejecting false problems that violated the five rule like in 5x18=93 than false problems respecting this rule). This occurred because young adults used two different strategies on each type of problems (i.e., a slow complete-verification strategy on match problems and a fast five-rule checking strategy on mismatch problems). Moreover, five-rule effects were larger under the high-mismatch ratio condition and smaller under the low-mismatch ratio condition, as compared to the equal-ratio condition. This arose because younger adults used the five-rule checking strategy more often when there were more problems violating the five rule and less often when fewer problems violated the rule. In other words, younger participants calibrated their strategy use to changing rates of strategies as well as to problem characteristics.

The most original findings in this experiment concern age-related differences in strategy selection. Older adults used a complete-verification strategy on all problems under the equal ratio condition, thereby obtaining comparable performance for the five match and mismatch problems. This suggests that older participants did not change strategies across trials but always used the same strategy (i.e., completeverification strategy), or did not change strategies sufficiently systematically as a function of problem types. The same conclusion was drawn by Duverne and Lemaire (2003) to account for similar findings of age-related decrease in split effects (see also El Yagoubi et al., in press).

Only in the high-mismatch ratio-condition did older adults show significant five-rule effects. This suggests that older participants are not necessarily as rigid as would be implied by the lack of strategy variability observed under the equal-ratio condition. Significant five-rule effects in older adults when tested under the high-mismatch condition suggest that both complete- and five-rule verification strategies are available to older adults. However, older adults used the five-rule strategy only when violation of five-rule was very salient, as in high-mismatch condition where $75 \%$ problems violated the five rule. 

why would they not use the five-rule strategies under the equal-ratio condition like younger adults? There are several possibilities. First, older people may have used the five-rule checking strategy under equal-ratio condition, but on fewer five, false, mismatch problems or less systematically than younger adults. Such lower frequency or level of systematicity decreases or absorb potential latency differences between match and mismatch problems. Second, it is possible that savings from using the fiverule checking strategy as compared from using the complete-verification strategy are less for older adults than for younger adults, unless the five-rule checking strategy is used on a high proportion of problems like under the high-mismatch ratio condition. Third, it is possible that this age-related difficulties in choosing strategies adaptively stems from a more general processing resource deficits. As suggested by Duverne and Lemaire's findings that age-related decrease in strategy selection is correlated with decreased processing speed, the present difficulties of older adults to select the appropriate strategies as a function of problem types and problem ratios stems from their slowed processing speed that prevents them from noticing problem and task features relevant to optimize strategy choices. A variant of this general processing speed hypothesis concerns age-related decrease in executive functions. Executive functions include, among others, the ability to switch among tasks, strategies, or information priorities (e.g., Miyake, Friedman, Emerson, Witzki, Howerter, 2000), and age-related differences have been found in executive functioning (e.g., McDowd, 1997; Kramer, Humphrey, Larish, Logan, \& Strayer, 1994). It is possible that age-related differences in executive functioning led older adults to be less adaptive in their strategy choices. Our data do not enable us to test this hypothesis that predicts that low-executive functioning individuals should be more impaired in their adaptive strategy choices than high-executive functioning participants. Future experiments may test this hypothesis directly. Finally, it is possible that older adults were fluent enough in arithmetic to prefer using the complete-verification strategy on all trials. The lack of main effect of age for true problems under equal-ratio condition is consistent with this latter hypothesis.

To further test for this hypothesis of arithmetic fluency, we ran two analyses. First, the mean latencies of the older adults were regressed on the mean latencies of the young adults. The best-fitting linear model was RTyoung $=1.02$ (RTolder) $-51\left(R^{2}=.94\right)$. Second, we conducted individual regression analyses for each participant (Lorch \& Myers, 1990) regressing RTs for true, non-five problems on an index of problem difficulty (i.e., correct product) in both young and older adults. Results showed no age differences in effects of problem size, as average slopes were .74 and $.80(F<1)$ in young and older adults, respectively. This result is interesting for two reasons. First, it is consistent with the hypothesis that older adults were very fluent at arithmetic. With this arithmetic fluency, they may have not found necessary to use the five-rule checking strategy to reject false, five mismatch problems. Second, it is consistent with previous findings showing that older adults compensate for the slower input and output stages (e.g., encoding, responding) by processing the central processing stages (e.g., retrieving basic facts from memory) more rapidly than younger adults (e.g., Allen et al., 1997; Geary et al., 1993).

Authors Note 
research was funded in part by the CNRS (French NSF) and the Cognitique programme of the French Ministère de la Rrecherche. We thank Agnès Arlaud and Anne Sophie Renaud for their help in data collection . Correspondence about the paper should be directed to Patrick Lemaire, LPC-CNRS \& Université de Provence, 3 Place Victor Hugo, Case 66, 13331 Marseille, France (email: lemaire@up.univ-mrs.fr).

\section{BIBLIOGRAPHY}

Allen, P. A., Ashcraft, M. H., \& Weber, T. A. (1992). On mental multiplication and age. Psychology and Aging, 7, 536-545.

Allen , P. A., Smith, A. F., Jerge, K. A., \& Vires-Collins, H. (1997). Age differences in mental multiplication: Evidence for peripheral but not central decrements. Journal of Gerontology: Psychological Sciences, 52b(2), 81-90.

Ashcraft, M. H., \& Battaglia, J. (1978). Evidence for retrieval and decision processes in mental addition. Journal of Experimental Psychology: Human Learning \& Memory, 4, 527-538.

Ashcraft, M. H., \& Stazyk, E. H. (1981). Mental addition: A test of three verification models. Memory \& Cognition, 9(2), 185-196.

Campbell, J. I. D., \& Graham, D. J. (1985). Mental multiplication skill: Structure, process, and acquisition. Canadian Journal of Psychology, 39, 338-366.

De Rammelaere, S., Stuyven, E., \& Vandierendonck, A. (2001). Verifying simple arithmetic sums and products: Are the phonological loop and the central executive involved? Memory and Cognition, 29, 267-274.

Duverne, S., \& Lemaire, P. (in press). Age-related differences in arithmetic problem verification strategies. Journal of Gerontology: Psychological Sciences.

Duverne, S., \& Lemaire, P., \& Michel, B. (2003). Alzheimer's disease disrupts arithmetic facts retrieval processes but not arithmetic strategy selection. Brain and Cognition, 52, 302-318.

El Yagoubi R, Lemaire P \& Besson M. (2003). Different brain mechanisms mediate two strategies in arithmetic: evidence from Event-Related brain Potentials. Neuropsychologia; 41(7), 855-862.

El Yagoubi, R., Besson, M, \& Lemaire, P. (in press). Effects of aging on arithmetic problem solving: An event-related brain potential study. Journal of Cognitive Neuroscience.

Folstein, M. F., Folstein, S. E., \& McHugh, P. R. (1975). Mini mental state: A practical method for grading the cognitive state of patients for the clinician. Journal of Psychiatric Research, 12(3), 189-198.

French, J. W., Ekstrom, R. B., \& Price, I. A. (1963). Kit of reference tests for cognitive factors. Princeton, NJ: Educational Testing Service.

Geary, D., \& Lin, J. (1998). Numerical cognition: Age-related differences in the speed of executing biologically primary and biologically secondary processes. Experimental Aging Research, 24(2), 101-138. 
Geary, D. C., Frensch, P. A., \& Wiley, J. G. (1993). Simple and complex mental subtraction: Strategy choice and speed-of-processing differences in younger and older adults. Psychology and Aging, 8, 242-256.

Geary, D. C., \& Whiley, J. G. (1991). Cognitive addition: Strategy choices and speed-of-processing differences in young and elderly adults. Psychology and Aging, 6(3), 474-483.

Kramer, A.F., Humphrey, J.F.L., Larish, J.F., Logan, G.D., Strayer, D.L. (1994). Aging and inhibition: Beyond a unitary view of inhibitory processing in attention. Psychology and Aging, 9, 4, 491-512.

Krueger, L. E. (1986). Why 2 x 2 = 5 looks so wrong: On the odd-even rule in sum verification. Memory \& Cognition, 14, 141-149.

Krueger, L. E., \& Hallford, E. W. (1984). Why $2+2=5$ looks so wrong: On the oddeven rule in sum verification. Memory \& Cognition, 12, 171-180.

LeFevre, J., Bisanz, J., Daley, K. E., Buffone, L., \& Sadesky, G. S. (1996). Multiple routes to solution of single-digit multiplication problems. Journal of Experimental Psychology: General, 125, 284-306.

LeFevre, J., Sadesky, G. S., \& Bisanz, J. (1996). Selection of procedures in mental addition: Reassessing the problem-size effect in adults. Journal of Experimental Psychology: Learning, Memory, and Cognition, 22, 216-230.

Lemaire, P. (1999). Le Vieillissement Cognitif. Paris: Presses Universitaires de France.

Lemaire, P., \& Fayol, M. (1995). When plausibility judgments supersede fact retrieval: The example of the odd ${ }^{\wedge}$ even effect on product verification. Memory and Cognition, 23(1), 34-48.

Lemaire, P., \& Lecacheur, M. (2001). Older and younger adults' strategy use and execution in currency conversion tasks: Insights from French Franc to Euro and Euro to French Franc conversions. Journal of Experimental Psychology: Applied, 3, 195-206.

Lemaire, P., \& Lecacheur, M. (2002a). Children's strategy use in spelling. Developmental Science, $5(1), 43-48$.

Lemaire, P., \& Lecacheur, M. (2002b). Children's strategies in computational estimation. Journal of Experimental Child Psychology, 82, 281-304.

Lemaire, P., \& Reder, L. (1999). What affects strategy selection in arithmetic? An example of parity and five effects on product verification. Memory \& Cognition, 22, 364-382.

Lemaire, P., \& Siegler, R. S. (1995). Four aspects of strategic change: Contributions to children's learning of multiplication. Journal of Experimental Psychology: General, 124(1), 83-97.

Masse, C., \& Lemaire, P. (2001). How do people choose among strategies? A case study of parity and five-rule effects in arithmetical problem solving. Psychological Research, 65(1), 28-33.

McDowd, J.M. (1997). Inhibition in attention and aging. Journal of Gerontology: Psychological Sciences, $52 B, 6,265-273$.

Miyake, A., Friedman, N.P., Emerson, M.J., Witzki, A.H., Howerter, A. (2000). The unity and diversity of executive functions and their contributions to complex tasks: A latent variable analysis. Cognitive Psychology, 41, 49-100.

Pesenti, M., Thioux, M., Seron, X., \& De Volder, A. (2000). Neuroanatomical substrates of arabic number processing, Numerical comparison, and simple addition: A PET study. Journal of Cognitive Neuroscience, 12(3), 461-479.

Raven, J. C. (1951). Guide to using progressive matrices (1947), Sets A, Ab, B. London: Lewis. 
Salthouse, T. A. (1996). "The processing-speed theory of adult age differences in cognition." Psychological Review, 103, 403-428.

Siegler, R. S. (1996). Emerging minds: The process of change in children's thinking. New York: Oxford University Press.

Siegler, R. S., \& Lemaire, P. (1997). Older and younger adults' strategy choices in multiplication: Testing predictions of ASCM using the choice/no-choice method. Journal of Experimental Psychology: General, 126(1), 71-92.

Stanescu-Cosson, R., Pinel, P., van de Moortele, P. F., Le Bihan, D., Cohen, L., \& Dehaene, S. (2000). Understanding dissociations in dyscalculia. A brain imaging study of the impact of number size on the cerbral networks for exact and approximate calculation. Brain, 123, 2240-2255.

Zbrodoff, N. J. (1999). Effects of counting in alphabet arithmetic: Oppotunistic stopping and priming of intermediate steps. Journal of Experimental Psychology: Learning, Memory, and Cognition, 25(2), 299-317.

Zbrodoff, N. J., \& Logan, G. (2000). When it hurts to be misled: A Stroop-like effect in a simple addition production task. Memory and Cognition, 28(1), 1-7.

Zbrodoff, N. J., \& Logan, G. D. (1990). On the relation between production and verification tasks in the psychology of simple arithmetic. Journal of Experimental Psychology: Learning, Memory, and Cognition, 16, 83-97.

\section{ABSTRACTS}

Young and elderly adults were asked to say whether a series of complex arithmetic problems were true or false so as to test five-rule effects. The five-rule effect in arithmetic problem verification tasks refers to faster and more accurate judgments for false equations when the proposed product matches the five rule (i.e., $N \times 5=$ product with a unit digit equal to 0 or 5 ; e.g., $5 \times 16=85$ ) than when it mismatches the rule (e.g., $5 \times 18=93$ ). Results showed better performance on match than on mismatch problems in young adults but equal performance in older adults. Moreover, five-rule effects were larger when $75 \%$ of problems mismatched the five-rule and smaller when $25 \%$ of problems mismatched the five rule, in young adults. Only under highmismatch condition did older adults show significant five-rule effects. Implications of these findings for further understanding age-related differences in arithmetic strategy selection and other high-level cognitive domains are discussed.

Des adultes jeunes et âgés devaient dire si une série de problèmes arithmétiques complexes étaient vrais ou faux, afin de tester les effets de cinq. Dans une tâche de vérification de problèmes arithmétiques, les effets de cinq consistent à observer de meilleures performances lorsque les problèmes violent la règle des cinq (i.e., $N \times 5=$ produit comprenant une unité égale à 0 ou 5 ; e.g., $5 \times 18=93)$ que lorsque les problèmes respectent la règle (e.g., 5x16=85). Les résultats ont laissé apparaître de meilleures performances sur les problèmes qui violent la règle, seulement chez les adultes jeunes. Par ailleurs, la taille de l'effet de cinq augmentait lorsque $75 \%$ des problèmes violaient la règle des cinq et diminuaient dans la condition où $25 \%$ des problèmes violaient la règle. C'est seulement dans la condition $75 \%$ de violation que les performances des adultes âgés laissaient apparaître des effets de cinq. Nous discutons les implications de ces résultats pour notre compréhension des variations stratégiques liées à l'âge en arithmétique et dans d'autres tâches cognitives de haut niveau. 
INDEX

Keywords: arithmetic , strategy , aging, five effects, verification task

\section{AUTHORS}

\section{PATRICK LEMAIRE}

CNRS-Université de Provence \& Institut Universitaire de France LPC-CNRS \& Université de Provence 3 Place Victor Hugo

Case 66

13331 Marseille, FRANCE

Tel: 33.4.91.10.62.24, Fax: 33.4.91.10.62.55

Email: lemaire@up.univ-mrs.fr

\section{MIREILLE LECACHEUR}

CNRS-Université de Provence 